Guest Editorial, part of a Special Feature on Advancing Social-Ecological Research Through Teaching: Social-Ecological Systems Framework and Design Principles in Large Areas

\title{
Advancing social-ecological research through teaching: summary, observations, and challenges
}

\author{
Natalie C. Ban ${ }^{1}$ and Michael Cox ${ }^{2}$
}

Key Words: case studies; frameworks; pedagogy; social-ecological research; social-ecological systems; teaching

\section{INTRODUCTION}

Much research on social-ecological systems (SESs; Ostrom 2009) and almost all of the work on the design principles (Ostrom 1990) stem from examples that cover small areas, yet most environmental issues occur across vast regions. There is thus a need to understand better whether and how these ideas apply to large SESs (Fleischman et al. 2014, Cox 2015). At the same time, it is urgent to move toward sustainable use of resources and management of common-pool resources (e.g., Poteete et al. 2010). In turn, improving understanding and management requires training of a new generation of scientists, managers, policy makers, and others who understand the literature and urgency of management for sustainability. However, teaching about SESs can be challenging because of their complexity and multidisciplinarity (e.g., Dieleman and Huisingh 2006).

The basis of this special feature is the need for better understanding of large SESs, plus a desire to teach concepts of complex SESs (thereby training the next generation of leaders) and learn from each other's teaching experiences. This special feature thus had two objectives: (1) provide examples and support for teachers committed to engaging students with ideas around complex SESs (Ban et al. 2015a, Cox 2015), and (2) provide a set of case studies led by or involving students that examines large case studies ( $>10,000 \mathrm{~km}^{2}$; Ban et al. 2015b, Lacroix and Richards 2015, Lancaster et al. 2015, Taggart-Hodge and Schoon 2016, Tyson 2017, Villamayor-Tomas et al. 2016).

\section{SUMMARY OF THE ARTICLES}

In the courses that formed the basis of most of the articles in this special feature (Ban et al. 2015a), students were tasked with exploring a theme or region of interest that covers a relatively large area as their course project. This special feature is the result of some very creative themes that students explored that simultaneously served to teach them the core issues in SESs, including Ostrom's design principles (Ostrom 1990) and the SES framework (Ostrom 2009), and has advanced and stretched ideas within this literature. Lancaster et al. (2015) reviewed the extent to which a large set of conservation areas, Rockfish Conservation Areas in British Columbia, Canada, met the design principles, and they found the conservation areas to warrant improvement on many of the principles. Taggart-Hodge and Schoon (2016) used the SES framework to illustrate many of the challenges facing a complex transboundary protected area, the East Carpathians Biosphere Reserve in eastern Europe. Tyson (2017) similarly used the SES framework to illustrate the advantages and limitations a large comanagement effort, the Inuvialuit Settlement
Region in northern Canada. Lacroix and Richards (2015) applied the design principles to the carbon tax in British Columbia, Canada, and found that their assessment added insights beyond those provided by existing policy analyses. Ban et al. (2015b) used a SES lens to examine changes in governance through time in the Great Barrier Reef Marine Park, Australia, assessing changes in property rights and multiple goods and ecosystems services.

Two articles specifically address teaching. Ban et al. (2015a) review the literature on pedagogical approaches to teaching complex themes such as SESs. They also provide examples from five university-level courses, share lessons learned, and provide the syllabi as appendices. Their publication has already proven to be a useful resource for other teachers starting or reformulating courses on SESs, with several teachers having contacted the authors to comment that they used the paper to inform their own course design. Cox (2015) provides a rubric for conducting empirical research in environmental social sciences. That publication is designed to be a helpful resource for teachers, who can use it as an introduction to the topic in courses, and for students and other researchers wishing to pursue environmental social science research.

\section{OBSERVATIONS AND CHALLENGES}

The courses from which most of the articles originated covered both the SES framework and the design principles. The courses used the social-ecological systems meta-analysis database (SESMAD 2014) as a tool for operationalizing the SES framework. In developing their case study papers, students were free to choose any approach, including applying the SES framework and using the design principles to analyze their case. We observed that although students conceptually understood and appreciated the SES framework, most found it difficult to apply. Some studies (Taggart-Hodge and Schoon 2016, Tyson 2017) used the SES framework as a tool to structure and describe their cases (e.g., describing the governance system, actors, resources, and external influences in their case study). These tended to be descriptive case studies. Those studies that took a more analytical approach all used the design principles to assess the effectiveness of management in their case studies (Lacroix and Richards 2015, Lancaster et al. 2015, Villamayor-Tomas et al. 2016). Drafts of several articles initially attempted to do both, i.e., use the SES framework and design principles, but ended up focusing on design principles only. Thus, we observed that students found it more straightforward to apply the design principles than the SES framework. We think this is because the design principles are more amenable to a "variable-oriented" science that breaks down a case 
into independent dimensions and examines the individual contributions of each of these to some outcome (see Ragin 2000). This is how the empirical cases tended to treat the design principles. Here, we discuss two challenges faced by students that are also more broadly reflected in the literature: how to implement the SES framework, and the role of scientific frameworks more generally; and how to conduct a SES case study.

\section{The social-ecological system framework and the role of scientific frameworks}

Despite best efforts by teachers in the courses, in the case studies, there is little indication of a common understanding of what it means to implement the SES framework. We think the issue extends beyond the classroom to the SES literature more broadly. There are at least two reasons for this. First, the framework is not accompanied by enough guiding materials regarding how it should be used to enable scholars to implement it consistently. Indeed, there do not exist any materials that guide a user in implementing the SES framework outside of specific implementations of it to particular cases, leaving each individual or research team to implement the framework as they see fit. Although the framework diagrammatically depicts a SES, there is no indication for how this depiction should be used to support a scientific analysis (but see Binder et al. 2013). The design principles, each conceivable as a binary variable, do not require such guidance and are more readily interpretable by scholars who are familiar with the standard quantitative social science paradigm.

A second reason that researchers find it challenging to implement the SES framework is that it is not clear what the role of a scientific framework should be, and relatedly, what makes for a successful scientific framework. Although there are many frameworks to support the analysis of human-environment interactions (Binder et al. 2013), there is little discussion on what their scientific role ought to be, other than providing a common scientific language. This situation contrasts with that of scientific theories. A good theory needs to be testable, and a better theory is one that that can make accurate predictions for novel data without ad hoc adjustments. No similar statement can be made about scientific frameworks. More specifically, there is very little discussion of how scientific frameworks can be used to support commonly accepted goals of science such as the production of causal inferences. Similarly, there is little discussion of how frameworks relate to the specific scientific steps of sampling, measurement, and analysis. Most frameworks are presented as essentially boxand-arrow diagrams, and the gap between this type of depiction and a well-understood integration of frameworks with a rigorous view of the scientific enterprise is potentially large.

Although we can agree that a framework should establish a common language for science, there is little common understanding of how a framework should accomplish this. Unanswered questions include: How do frameworks support the expression and testing of theories? Is it by providing the variables that a theory would rely on to express a causal narrative and mechanism? If so, the SES framework is ambiguous in its ability to accomplish this function. It is unclear which of the objects it contains can be readily understood and therefore expressed as variables, and for those that can, there is no guidance offered for how these variables should be operationalized in a theory or in an empirical test of a theory.

\section{Conducting social-ecological system case studies}

Another question that arises from the case studies is: What does it mean to conduct a case study on a SES? Although there are established texts on how to conduct such analyses for purely social systems (e.g., Yin 2013), and Cox (2015) mentions some common qualitative techniques that are relevant to small-sample socialecological analysis, no authoritative book-length text has been developed. Thus, SES case studies to date range widely in the methods used, with some attempting empirical assessments and others taking descriptive approaches. With respect to the design principles, it is not clear what the role of quantitative measurement should be in a single, or even comparative, case study. The concern here is familiar: that there is the possibility that what is being measured in a given case is more noise than signal, which is essentially the reason for collecting more data, to discern patterns and distinguish them from other random dynamics. A reasonable response to this is that such measurement is done in the context of a thick understanding of the mechanisms occurring in the particular case, such that causal inference relies less on counterfactuals and comparisons and more on mechanistic understandings of how a suite of variables plays out in a particular case. With respect to the SES framework, we can ask: What is its role in conducting individual case studies? This is an important question, for it may be that this is where the framework has the most potential: in helping an analyst unpack the complexity of a case into components and their interactions. If this is true, it would be beneficial to establish this function further by more formally integrating the topics of socialecological frameworks and social-ecological case studies.

\section{CONCLUSION}

This special feature provides examples and support for teachers committed to engaging students with ideas around complex SESs and provides a set of case studies, led by or involving students, that focus on large systems. The cases provide additional examples of the growing use and assessment of both the SES framework and the design principles. In the process of developing this special feature, several observations arose about the state of the SES field of inquiry more broadly: (1) the SES framework is not used consistently and has limited guidance on how to use it, leading to questions about the use of frameworks more broadly; and (2) there is little consistency, or guidance, for how to conduct SES case studies, leading to a range of approaches. Although we do not provide answers to these issues, we hope that raising them will provoke conservations that can ultimately lead to improved guidance for researchers, helping the field of SESs grow in the future.

Responses to this article can be read online at: http://www.ecologyandsociety.org/issues/responses. php/8949
Acknowledgments:
NCB thanks SSHRC for support for this special feature. 


\section{LITERATURE CITED}

Ban, N. C., E. Boyd, M. Cox, C. L. Meek, M. Schoon, and S. Villamayor-Tomas. 2015a. Linking classroom learning and research to advance ideas about social-ecological resilience. Ecology and Society 20(3):35. http://dx.doi.org/10.5751/ ES-07517-200335

Ban, N. C., L. S. Evans, M. Nenadovic, and M. Schoon. $2015 b$. Interplay of multiple goods, ecosystem services, and property rights in large social-ecological marine protected areas. Ecology and Society 20(4):2. http://dx.doi.org/10.5751/ES-07857-200402

Binder, C. R., J. Hinkel, P. W. G. Bots, and C. Pahl-Wostl. 2013. Comparison of frameworks for analyzing social-ecological systems. Ecology and Society 18(4):26. http://dx.doi.org/10.5751/ es-05551-180426

Cox, M. 2015. A basic guide for empirical environmental social science. Ecology and Society 20(1):63. http://dx.doi.org/10.5751/ es-07400-200163

Dieleman, H., and D. Huisingh. 2006. Games by which to learn and teach about sustainable development: exploring the relevance of games and experiential learning for sustainability. Journal of Cleaner Production 14(9-11):837-847. http://dx.doi.org/10.1016/ j.jclepro.2005.11.031

Fleischman, F. D., N. C. Ban, L. S. Evans, G. Epstein, G. GarciaLopez, and S. Villamayor-Tomas. 2014. Governing large-scale social-ecological systems: lessons from five cases. International Journal of the Commons 8(2):428-456. http://dx.doi.org/10.18352/ ijc. 416

Lacroix, K., and G. Richards. 2015. An alternative policy evaluation of the British Columbia carbon tax: broadening the application of Elinor Ostrom's design principles for managing common-pool resources. Ecology and Society 20(2): 38. http://dx. doi.org/10.5751/ES-07519-200238

Lancaster, D., D. R. Haggarty, and N. C. Ban. 2015. Pacific Canada's Rockfish Conservation Areas: using Ostrom's design principles to assess management effectiveness. Ecology and Society 20(3):41. http://dx.doi.org/10.5751/ES-07815-200341

Ostrom, E. 1990. Governing the commons: the evolution of institutions for collective action. Cambridge University Press, Cambridge, UK. https://doi.org/10.1017/CBO9780511807763

Ostrom, E. 2009. A general framework for analyzing sustainability of social-ecological systems. Science 325:419-422. http://dx.doi.org/10.1126/science.1172133

Poteete, A. R., M. A. Janssen, and E. Ostrom 2010. Working together: collective action, the commons, and multiple methods in practice. Princeton University Press, Princeton, New Jersey, USA. http://dx.doi.org/10.1515/9781400835157

Ragin, C. C. 2000. Fuzzy-set social science. University of Chicago Press, Chicago, Illinois, USA.

SESMAD. 2014. Social-ecological systems meta-analysis database: background and research methods. Dartmouth College, Hanover, New Hampshire, USA. [online] URL: http://sesmad. dartmouth.edu/
Taggart-Hodge, T. D., and M. Schoon. 2016. The challenges and opportunities of transboundary cooperation through the lens of the East Carpathians Biosphere Reserve. Ecology and Society 21 (4):29. https://doi.org/10.5751/ES-08669-210429

Tyson, W. 2017. Using social-ecological systems theory to evaluate large-scale comanagement efforts: a case study of the Inuvialuit Settlement Region. Ecology and Society 22(1). https:// doi.org/10.5751/ES-08960-220105

Villamayor-Tomas, S., M. Avagyan, M. Firlus, G. Helbing, and M. Kabakova. 2016. Hydropower vs. fisheries conservation: a test of institutional design principles for common-pool resource management in the lower Mekong basin social-ecological system. Ecology and Society 21(1):3. http://dx.doi.org/10.5751/ES-08105-210103

Yin, R. K. 2013. Case study research: design and methods. Fifth edition. Sage, Thousand Oaks, California, USA. 